\title{
Elimination of Distractors: A Construct-irrelevant Strategy? An Investigation of Examinees' Response Decision Processes in an EFL Multiple- choice Reading Test
}

\author{
Godefroid B. Katalayi \\ Institut Supérieur Pédagogique de Kananga, DR Congo
}

\begin{abstract}
This paper investigates the use of elimination of distractors strategy by exploring examinees' response decision processes while answering test items. It aims to evaluate the extent to which examinees' use of elimination of distractors strategy is construct-irrelevant. As instrument, the paper uses verbal reports in order to elicit response decision processes the selected six respondents used when they eliminated item options in some selected test materials. The results indicate five main patterns of response decision processes respondents used when eliminating distractors. However, of these five patterns, four patterns include response decision processes that can be qualified construct-irrelevant to reading construct; while one pattern included response decision processes that appear to be construct-relevant. This suggests that the use of elimination of distractors is a strategy that can sometimes be construct- relevant.
\end{abstract}

Index Terms - elimination of distractors, construct-relevant strategy; construct-irrelevant strategy, reading construct, response decision processes, EFL multiple-choice reading test

\section{INTRODUCTION}

The conventional MC question consists of examinees evaluating a number of suggested options before choosing only one option as the answer. Although examinees may not identify the correct answer, they are however certain that some of the options are incorrect (Bradbard, Parker, \& Stone, 2004). However, one of the major concerns regarding this test format is that examinees' number of correctly answered questions is composed of two numbers: the number of questions to which they actually know the answer, and the number of questions to which they correctly guess the answer (Bradbard, et al., 2004). This issue has generally been addressed in terms of test-wiseness strategies. The underlying assumption is that examinees utilize the characteristics and format of the test in order to receive a high score (Sarnaci, 1979). Researchers have supported that the characteristics of an item can influence examinees' scores as some examinees may get some answers right without necessarily knowing the content of these items or using the skill that is being tested (Lee, 2011; Ascalon et al., 2007; Haladyna, Downing, \& Rodriguez, 2002). Viewed from this test wiseness perspective, examinees' scores on a multiple choice test are generally considered to include irrelevant variance; and this threatens the test construct validity (Bakker, et al., 2008; Messick, 1989; Haladyna et al., 2002). Among the test wiseness strategies reported in the literature, guessing and elimination of distractors appear to be the most important; and these two strategies are interrelated. This paper, however, investigates the use of elimination of distractors strategy by exploring examinees' response decision processes while answering test items.

\section{BACKGROUND}

In reviewing literature on test wiseness, Sarnacki (1979) summarizes three theoretical perspectives that appear to dominate the concept of test wiseness. The first perspective considers test wiseness as function of poor test construction; and this perspective premises that examinees generally use the clues in poorly written items in order to increase their test scores. The second perspective views test wiseness as an attribute of some individual examinees with high mental abilities and who profitably utilize some strategies in order to get some test items right without necessarily having the knowledge of the content tested. Finally, the third perspective is the synthesis of the first two; suggesting that test wiseness encompasses both the method of measurement, and the examinee characteristics. This perspective argues that neither perspective alone is sufficient in explaining the test wiseness construct and only a combination of both perspectives can offer necessary information concerning test wiseness. However, in all these three theoretical perspectives, test wiseness is considered to depress test validity and reliability as it introduces variance in test scores that is unrelated to the construct being measured (Sarnacki, 1979).

Guessing, as an overarching concept in test wiseness research, is a strategy examinees use to eliminate one or some of the item options as incorrect. If such elimination is successful, it increases the probability that the option selected is the correct one; suggesting that elimination of distractors is an element of guessing (Sarnaci, 1979). The theoretical 
underpinning of elimination of distractors strategy is the deductive reasoning process. Sarnaci (1979) argues that deductive reasoning is dependent on some knowledge of the tested material. However, the correct answer is not known without the presence of other choices that serve as cues in the reasoning process. In line with this argument, Katalayi (2014) argues that, in the deductive reasoning process, in order to select the correct option, the examinee goes through the different options and starts to eliminate those options he/she finds are virtually incorrect because these options are not consistent with the information contained in the item question. Gibb (1964) calls this deductive reasoning strategy as the absurd options strategy; a strategy that consists of eliminating options that express the same fact, are opposite in meaning, or are simply nonsensical to the content being tested. Test wiseness studies that have used Gibb's absurd options strategy (see Bajtelsmit, 1975; Sarnaci, 1979) have concluded that in test wiseness examinees recourse to deductive reasoning when test items are written in a way to provide them with some clues. Viewed from this deductive reasoning stance, the elimination of improbable options has been strongly associated with skills irrelevant to the test construct; therefore, generating construct-irrelevant variance in test scores.

Although research has investigated test wiseness construct from multiple perspectives including its components (Nilsson \& Wedman, 1974), correlates (Diamond \& Evans, 1972), measurement (Millman, 1966), teachability (Oakland, 1972), and application (Ford, 1973), research focusing on elimination of distractors is extremely limited to few aspects (Stathopoulou, \& Nikaki, 2009). One aspect relates to instances when examinees use test-taking strategies to eliminate some distractors (Lee, 2011). It was found that examinees eliminated options that included information that was contradictory to paragraph/overall passage. In earlier studies, Slakter et al., 1970, and Langer, Wark, and Johnson, 1973, cited in Sarnaci (1979), reported that examinees eliminated options that expressed the same fact since these options implied each other's incorrectness. They called this principle 'similar options' or 'similar meaning'. The similar options principle has been included in the development and experimentation of instruments to measure test wiseness (; Sarnaci, 1979; Crehan et al., 1974). On their part, Langer et al., (1973) found that examinees usually eliminated options that were opposite in meaning and confidently eliminated at least one of the options on the assumption that the correctness of one implies the incorrectness of the other.

Another aspect of research focus relates to the development of scoring methods that tend to reducing elimination of distractors so as to improve the psychometric quality of MC tests (Lau, Lau, Hong, \& Usop, 2011; Oh, 2004; Chang, Lin, \& Lin, 2007). These scoring methods rely on the assumption of partial knowledge that supports that examinees' knowledge of any MC item can be any one of full knowledge, partial knowledge, absence of knowledge, partial misconception, and full misconception; therefore, any attempt to measure knowledge dichotomously with a pass or fail score is unsatisfactory (Lau, et al., 2011; Bradbard, Parker, \& Stone, 2004; Chang, et al., 2007; Alexander, Bartlett, Truell, \& Ouwenga, 2001). These methods criticise the dichotomous scoring of an item on the ground that it does not credit examinees' partial knowledge; therefore, teachers cannot diagnose examinees' misunderstanding and lack of understanding as this can serve to provide informative feedback necessary for facilitating students' continuous learning. One of these scoring methods is the number right elimination testing (NRET) that combines elements of number right (NR) scoring technique and elimination testing (ET) technique (Lau, et al., 2011). In this method, examinees are instructed to choose either "correct," or "wrong," or "not sure" for any of the option; and for any MC item with four options, one mark is awarded for each wrong option eliminated correctly, three marks are deducted if the correct answer is eliminated, one extra mark is awarded for any correct answer selected, and no mark is awarded for choosing "not sure" (Lau, Lau, Hong, \& Usop, 2011).

However, viewed the psychometric nature of the few studies on elimination of distractors strategy and their limited scope, little is known about the response decision processes examinees actually use when eliminating distractors. Yet, an understanding of these decision processes can help conclude whether or not elimination of distractors is a constructirrelevant strategy. This is to suggest that, unless we can tell what examinees actually do when eliminating distractors during test taking process; we cannot a priori assume that the selection of this strategy is a poor choice examinees make to answer specific test items.

\section{Elimination of distractors in multiple-choice reading tests}

This paper tests the assumption according to which elimination of distractors is a construct-irrelevant strategy that brings variance in examinees' test scores on the ground that examinees use this strategy to get some answers right even though the selected option is not understood (Lee, 2011). Focusing on the use of this strategy in multiple-choice reading tests, the paper aspires to gain an understanding of how elimination of distractors strategy can be used as part of the process of construct validation. Hence, it is premised that an investigation of examinees' actual response decision processes in answering test items can provide insights into an understanding of the extent to which examinees' use of elimination of distractors is construct-irrelevant.

As a test taking strategy, elimination of distractors is a conscious process that examinees use to answer some test items. Alderson (2000) and Rupp, Ferne and Choi (2007) argue that readers adjust their strategies and engage in the type of comprehension processes that most suit their purpose for reading. Therefore, since the main purpose of responding to $\mathrm{MC}$ questions is to answer them correctly, examinees select their strategies accordingly in order to optimize their chances for success. To Rupp, et al., (2007), factors that potentially influence the selection of strategies in testing situations relate to the level of linguistic difficulty of the text, the topic of the text, the linguistic level of the questions, the content and phrasing of the questions, the location of information from the correct answers and the 
distractors, as well as the level of cognitive activity required of the examinees. On their part, Embretson and Wetzel (1987) use the concept of text mapping (a process of relating the information in the item question and response options to the information in the text) and they argue that difficulty in answering an MC reading item is influenced by the amount of information needed from the text to answer individual test questions. They argue that, if the relevant information necessary for answering an individual test item is contained in a single short sentence, text mapping will be expected to be easy; whereas if the relevant information necessary for answering an individual test item is spread throughout the text, text mapping will be expected to be difficult (Embretson \& Wetzel, 1987).

In a study that aimed to investigate the taxonomy of test-taking strategies used by second language learners in answering multiple-choice reading questions, Lee (2011) found three underlying processes where examinees proceeded to eliminate distractors to achieve an answer; including when examinees have a vague sense that the other options cannot be correct; when they find option(s) that are contradictory to paragraph/overall passage meaning; and when they find options whose information is not mentioned in designated paragraph/text. However, Lee's taxonomy does not appear to rely on the conceptualization of construct validity of multiple-choice reading test. This conceptualization suggests that an MC reading test is valid if examinees' scores can provide an indication that they have read the text and understood it, that they have read the individual test questions and they have understood the questions' expectations, and that they have understood the meanings and implications of all item options (Katalayi, 2014). Yet, in light of this conceptualization of construct validity, investigating the response decision processes examinees use when eliminating distractors can offer a better taxonomy necessary to relate the examinees' response decision processes to the test construct.

\section{Conceptual scope}

The paper draws its conceptual underpinning from Embretson and Wetzel (1987)'s response decision processes as articulated in their model of reading. Embretson and Wetzel's (1987) model describes three response decision processes: encoding and coherence processes, text mapping and evaluation of the truth status of response options. During encoding and coherence processes, the examinee attempts to convert the visual stimuli of the text into meaningful representation (encoding) as well as connecting word meanings and different text propositions into a meaningful representation of the text (coherence) (Embretson \& Wetzel, 1987). During text mapping, the examinee attempts to relate the information in the item question and response options to the information in the text. Therefore, Embretson and Wetzel (1987) model posits that difficulty in text mapping is influenced by the amount of information needed from the text to answer individual test questions (Embretson \& Wetzel, 1987). They argue that if the relevant information necessary for answering an item is contained in a single short sentence, text mapping will be expected to be easy. Conversely, if the relevant information necessary for answering an item is spread throughout the text, text mapping will be expected to be difficult. Finally, during the evaluating of the truth status of response options, the examinee falsifies and confirms the response option (Embretson \& Wetzel, 1987). These two decision processes (falsification and confirmation) describe the extent to which examinees can use text information to make decision regarding the item options. During the falsification stage, the examinee attempts to falsify as many response options as possible while during the confirmation stage, the examinee compares the outstanding response option to the text passage to determine if the text confirms the response as correct.

\section{Objectives}

- Identify the response decision processes examinees use when they eliminate distractors in answering multiplechoice reading items;

- Evaluate the extent to which examinees' use of elimination of distractors strategy is construct-irrelevant.

\section{Context: The DR Congo English state examination}

The paper investigates the response decision processes examinees conduct when answering the DR Congo English state examination; an EFL test used as a subtest of the national test administered to final year secondary school students for certification. The ESE is a paper-and-pencil multiple-choice reading test using the conventional format that requires examinees to select only one option from a list of five suggested options.

\section{METHOD}

\section{Protocol analysis}

The paper uses protocol analysis methodology in order to explore the response decision processes examinees use when they eliminate distractors in answering multiple-choice reading questions. This method is used to uncover psychological processes that a person goes through while performing a task (Ericsson \& Simon, 1993). It premises that it is possible to verbalize examinees' thoughts in a way that does not alter the sequence of thought that mediate the completion of the task (Ericsson \& Simon, 1993). In using protocol analysis in this study, the underlying assumption is that the way respondents search for text information, evaluate item options, and choose their answers can be registered through their verbalizations, and this can be analysed to discover their response decision processes.

\section{Instruments: verbal reports and test materials}

Verbal reports

The paper uses verbal reports in order to elicit response decision processes respondents use when they eliminate item options. More specifically, the paper relies on Cohen and Upton (2006)'s taxonomy of verbal reports and it uses a 
combination of self-observation reports and self-revelation reports; two instruments that are meant to disclose respondents' stream-of-consciousness of thought processes when they eliminate distractors. Self-observation reports are used to enable the researcher identify respondents' specific behaviours while they eliminate options; whereas selfobservation reports are meant to reveal the respondents' reasons for eliminating certain options while searching for the correct answer (Cohen \& Upton, 2006). As suggested in the literature (Cohen \& Upton, 2006; Ericsson \& Simon, 1993), in order to accurately reflect participants' cognitive processes, the respondents' reports were collected during task completion.

\section{Test materials}

Three test papers were randomly selected from the 2013, 2014 and 2015 ESE editions. Each test paper contained a text whose length varied between 461-477 words; and it was followed by eight questions based on the comprehension of the text; thus, making a total of 24 items. The text in the test paper \#1 was about the consequences a young couple experiences with AIDS. The text in test paper \#2 was about trouble between students and the police as a result of a conflict between students from two neighbouring schools. Finally, the text in test paper \#3 was a retold tale of a hungry fox and a group of geese from a farm-house.

Participants

The verbal reports were administered to six students (2 high achieving students, two average achieving students, and 2 low achieving students) randomly selected from a class list of 47 students on the basis of their results to their class marks in English. All the six respondents reported some familiarity with the MC technique as this was part of their classroom assessment methods.

Participants' profile

\begin{tabular}{|l|l|l|l|l|l|l|l|}
\hline $\begin{array}{l}\text { Participant } \\
\text { identification }\end{array}$ & Gender & \multirow{2}{*}{ Age } & \multicolumn{2}{|l|}{ Linguistic background } & Test paper & $\begin{array}{l}\text { Class mark } \\
\text { selected }\end{array}$ & $\begin{array}{l}\text { Test mark } \\
/ 10\end{array}$ \\
\cline { 3 - 8 } & & & L1 & Other languages spoken & Paper \#2 & 4 \\
\hline Participant \#1 & M & 19 & Ciluba & French, Lingala, Swahili & Paper \#1 & 8 \\
\hline Participant \#2 & M & 18 & Lingala & French, Ciluba, Lingala & Paper \#2 & 5 & 7 \\
\hline Participant \#3 & F & 20 & Ciluba & French, Swahili, Lingala & Paper \#3 & 6 & 6 \\
\hline Participant \#4 & M & 19 & Swahili & French, Lingala, Ciluba & 6 \\
\hline Participant \#5 & F & 20 & Kikongo & French, Lingala, Ciluba & Paper \#1 & 8 & 8 \\
\hline Participant \#6 & F & 19 & Swahili & French, Ciluba, Kikongo & Paper \#2 & 5 & 3 \\
\hline
\end{tabular}

\section{Data collection procedure}

Piloting verbal reports

A pilot study was conducted in order to test and refine the two verbal protocols in terms of the administration procedure, and the kind of prompts to be used to elicit data. The pilot study included three respondents whose profile was similar to the six respondents retained in the study; but who were not retained to participate in the main study. The results of the piloting stage enabled the researcher to devise the instructions to be provided to participants and how the respondents could familiarise themselves with the task. Furthermore, it also enabled the researcher to make sense of the average time needed by each respondent to complete the task as well as the kind of prompts the researcher needs to elicit respondents' verbalisations.

\section{Data collection}

Six sessions were organised to collect data from the six respondents; in terms of one session per respondent. During each session, two phases were observed. During the first phase of each session, that lasted about 30 minutes, the researcher briefed the respondents by informing them that they were going to write an English test and he instructed them to select one test paper from the three test papers. He informed them that, contrary to the normal test, they had to verbalize their thoughts while answering the test questions. He advised them to use any language/s of their choice. Then after, the respondents were given some practice so as to familiarize themselves with the task. This practice consisted in the researcher reading a similar test paper and trying to verbalize his thoughts while answering test questions.

During the second phase, that was video-recorded and that lasted about two hours per respondent, each respondent had to complete the test task keeping in mind that he/she had to verbalize his/her thoughts while attempting to find answers to the test questions. Respondents' reports included their verbalizations of the response decision processes they had used to answer the questions as well as their responses to the researcher questions. The researcher's questions mainly aimed at gaining some clarification on respondents' choices to use particular processes or make particular decisions when eliminating item options.

\section{Data analysis}

Transcribing and translating the reports

The respondents' reports were first transcribed; and since all the six respondents had used mainly French and a mixing of French and their L1, the reports were then translated in English for analysis.

Item selection and coding

Although the six respondents answered all the eight items, the analyses were conducted only with test items where they used elimination of distractors strategy. Therefore, of the 24 items included in the three test papers, only 12 were selected for analysis. A continuous code was given to the 12 items. Thus, test paper \#1 included five items that were 
coded item \#1, item \#2, item \#3, item \#4, item \#5; test paper \#2 included 4 items coded item \#6, item \#7, item \#8, item \#9; and finally, test paper \#3 included 3 items coded item \#10, item \#11, and item \#12.

Operationalizing response decision processes used in eliminating distractors

In order to investigate the response decision processes respondents used when eliminating distractors, the paper builds on the main assumption of the construct validity of MC reading tests that suggests that a reading test is valid when examinees' scores on the test can provide an indication that they actually attempted to read the text and understand it, understand the expectations of the test questions, and understand the meanings and implications of the items options (Katalayi, 2014). In light of this assumption, the response decision processes used when eliminating distractors were explored in terms of three variables; including (a) read and understand the text or part of the text where the information necessary for answering the item is located; (b) understand the expectation of the question; and (c) understand the meanings and implications of all/some options. It is hypothesized that if elimination of distractors strategy is used when examinees use all of these three response decision processes in answering an individual item, this strategy is highly construct-relevant. Otherwise, it is a construct-irrelevant strategy.

\section{RESUlTS, DiSCUSSION AND CONCLUSION}

In reviewing the response decision processes the six respondents used when eliminating distractors in answering the twelve items, the following response decision processes emerge:

1. Reads the text, but does not understand the expectations of the question; understands the meanings and implications of (some) options [item \#1, item \#9]

The striking feature in the use of this response decision process is that, although the respondents attempted to read and understand the text; their attempts to understand the question expectation was either partial (for item \#1) because of a vague sense they had on the five options as a result of just skimming them; or unsuccessful (for item \#9) because of failure to understand that the phrasing of the question through the use of "except" in the question as this requires finding the option whose information is not included in the text. Therefore, respondents eliminated some options before deciding to select their answer by guessing among outstanding options.

I answering item \#1, respondent \#2 read the text and seemed to understand the expectations of the question. However, since the question required reading the entire text every time he had to read each option in order to falsify it, he therefore decided to read only some options and eliminated the options out of a vague sense that they could not be the answer. This excerpt from respondent's verbalization can act as evidence:

[Skims the text; but looks annoyed] I eliminate option 1; the last paragraph must be the conclusion of the story. [Skims the remaining four options] Option 5 must be also eliminated: this is the first paragraph; it is the introduction of the story. [Skims the text; and then rereads the question] I don't see where the text mentions the event that affects Yasekuru's life. [Researcher asks: So what are you going to do?] [Respondent replies] I'm going to guess from options 2,3 , and 4.

In answering item \#9, respondent \#6 demonstrated a good understanding of the text and the five options; but she failed to understand the implication of the use of the word "except" in the question as the inclusion of this word requires looking for an option whose information is not in the text. Therefore, the respondent failed to relate information in the options to the information requested in the test question. This extract can illustrate this point:

[Skims the text; and then inspects all the options] Option 1 is correct; they [students] used the pieces of stones. But let me look at other options [Goes back to the text] Oh! option 2 is also correct. How can we have 2 good answers? [Researcher asks: "What do you do then?] [Respondent replies] I must read the other options. [Reads the outstanding options, then skims the text, and rereads the options] I feel that options 3, 4 and 5 are also good answers. [Looks confused] Ok; I can eliminate 3 and 4. So I keep 5 as answer. [Researcher asks: Why do you eliminate options 3 and 4 when you say they are also good answers?] [Respondent replies confidently] It is because there must be only one answer.

2. Does not read the text; but understands the question's expectations; and understands the meanings and implications of (some) options [item \#2, item \#3, item \#6, item \#8, item \#11]

The striking feature of all the five items where respondents used this response decision process is that the respondents answered the test items without reading and comprehending the text or part of the test where the information necessary for answering the question was located; posing ipso facto the question of validity of their answers. However, the respondents demonstrated a good degree of understanding of the question expectation through reading and rereading it; and they also demonstrated a high level of understanding of the options and the underlying implications through scanning individual options.

In answering item \#2, respondent \#2 ignores reading the text and starts eliminating all options that are not logical, and/or do not address the issue presented in the question stem, or again that lie outside of the realm of plausibility. This excerpt can illustrate the position:

[Reads the question; then scans the five options] Option 5 must be eliminated; death cannot be the last decision one can take. [Reads other options; and carefully reads option 4] It is illogical to avoid AIDS by marrying a man with many sexual partners. [Rereads the remaining options] I also eliminate option 2; AIDS-related complications cannot be a decision one can take. 
In answering item \#3, respondent \#5 combined two response decision processes. First, she did not read the text information but she eliminated options 3 and 5 on the basis of her understanding the question's expectations and the meanings and implications of these two options: (Look! option 5: is illogical. "She" must relate to a singular noun; so it must be eliminated. Option 3 is not a good option because Kirongozi is a man, the husband of Yasekuru). Then, she goes back to the text, reads it and goes back to the outstanding options, considers one option (options 1); but still, she rereads options 2 and 4 for confirmation and finally eliminates these two options and confirms option 1 that was considered earlier. Here is an excerpt of the description of her response decision process:

Now I remain with 3 options. Let's see option 1. [Reads the text where the pronoun she is underlined]. Yes! It is written here: 'At the outset Asha seemed to be in good health. Yet, she stopped gaining weight and contracted one infection to another'. So the answer is 1 .

In answering item \#6, respondent \#1 eliminates two options (option 3 and option 4) on the basis of some clues provided in the question. Furthermore, he uses deductive reasoning to eliminate option 5 because it is not plausible in light of information requested in the test question. Recalling the text content; but not reading the part of the text where the pronoun 'his' is located, he eliminates option 3 and option 4 on the basis of his knowledge of grammar. This excerpt can act as evidence:

Options 3 and 4 must be eliminated; there must be a singular noun phrase to refer to his. [Then reads the outstanding options] Oh yes; option 1 must also be eliminated because the text speaks of many policemen; so his cannot refer to police. [Reads carefully the two outstanding options] Ok; I also eliminate option 5; [because] the lorry driver does not have companions. In the text, he is alone.

In answering item \#8, respondent \#3 eliminates an option that does not respond to the question being asked; and then she has recourse to her background knowledge in order to eliminate all options that do not address issues presented in the question. One particularity of this item is that the respondent gets the correct answer simply because this is the outstanding option although she is not sure of it as correct answer. The following excerpt can act as evidence of the respondent' use of this response decision process:

I really don't know the answer. [Pause] But let me read the question again. [Pause] Yes, I see; the question asks for what you can say for revealing the identity. Oh look; option 3 is wrong; it asks for the age; not identity; so I eliminate it. [Rereads carefully the other options] Also, option 4 is also wrong because it asks about the time of the incident; not the identity. [Researcher asks a question: What do you mean by identity?] [Respondent replies] My name, who my parents are, my tribe, etc. [Then continues reading options; looks at option 1] Yes; who killed the student? I think this is the answer. Let's look now at the two remaining options. [Researcher asks a question: Why do you look at remaining options when you have already the answer?] [Respondent replies] I must make sure that the two remaining options are wrong. Ok; option 2; no this is a wrong answer; it asks for the number of people involved in the accident. Option 5; no this is wrong. So the answer is option 1. [Researcher asks a question: Are you sure of option 1 as the answer?] [Respondent replies] I think it is the answer; because the other options are wrong.

Finally, in answering item \#11, respondent \#4 ignores to read the text and relies on his knowledge of the rule that governs the use of tag questions and eliminates all options that deviate from the rule. He feels confident of the answer option he has selected as this is the only outstanding option. The following excerpt illustrates respondent's use of this response decision process:

I eliminate option 2 first because the verb is in the present tense. [Researcher asks] Why do you think options with verbs in the present tense are wrong answers? [Respondent replies] Because the verb in the question is past; not present. [Then looks at other options] Oh I see, the answer must not be with a verb in affirmative form; so I must eliminate options 3, 4 and 5. So the answer must be option 1. [Researcher asks] Why do you believe option 1 is the good answer? [Respondent replies] This is because the other four options are wrong answers.

3. Reads and understands the text, understands the question expectation, understands the meanings and implications of the options [item \#4, item \#7]

The particularity of these two items is that they used all the three processes deemed necessary for answering MC reading items; however, respondents' use of elimination of distractors strategy aimed only to falsify and confirm their answer choices.

In order to answer item \#4, respondent \#5 demonstrates a good understanding of the text and the question's expectations and she conducts multiple readings of the text or she recalls information from the text prior to eliminating the wrong options. Furthermore, she makes use of her inferencing skills to eliminate other options; and finally she rereads the outstanding options, evaluates them and finally selects the answer option on the basis of her understanding of the text. The following extract illustrates the respondent' use of these response decision processes:

The question asks for an option whose information is not in the text. [Researcher asks: How do you know that you must select the option that contains information not stated in the text?] [Respondent replies] I know it from the word except. So, I must eliminate all options that contain information that is not stated in the test. [Reads carefully the options] Let's take option 1: I remember; Yasekuru decided not to get marriage again. I provisionally eliminate it; but I shall come back to it later. [Moves on to option 2] Yes, Kirongozi was a taxi driver who died of AIDS. So I can say that he suffered of a disease that was known. I also eliminate this option. [Moves on to option 3] Let me read it first. [Pause] $\mathrm{Ah}$; it is difficult to say something now. Let me read the text. [Skims the text] It is not clear I shall come back later. 
[Moves on to option 4] Yes, the man was a taxi driver; I remember; it is said in the text. So I also eliminate option 4. [Moves on to option 5] Let me read the text. Ok; look it is written here: 'Yasekuru's husband of eight years died of Aids-related complications'. So I must eliminate also this option. [Researcher asks: Now the answer is option 3, because this is the only option you have not eliminated?] [Respondent replies] I said I provisionally retained option 3; let me reread the text again. [After scanning the text portion where information is located] Ah the text does not say this; but I can deduce that people with many sexual partners are easily infected. But since the text does not say it clearly, this is the option that contains information not stated in the text. So, it is the correct answer.

In answering item \#7, respondent \#1 reads the text and demonstrates a good understanding of text main ideas and details, he then reads the question and displays an understanding of the question expectation; next he eliminates the options after understanding their meanings and implications either by going back to the text and scanning necessary information, or by recalling text information; and finally he rereads the text to confirm the answer option selected. The following excerpt is a verbalization of the respondent's response decision processes:

The question asks me to find the information that does not relate to the text; so I must start by reading the text the first time. [After careful reading of the text] Yes, I see; the text say: "furious young men were feverishly throwing to their opponents any kind of harmful objects: pieces of stones, bricks, iron sticks..."; so I eliminate option 1 because this is the information contained in the text. [Moves on to option 2] Ah; no idea now [Moves on to option 3; scans portion of the text] Yes, I see; the text says: "APOLOSA, a well-known policeman, was seriously injured"; yes; it is true. So I must also eliminate option 3. [Moves on to option 4; scans a portion of the text] Yes, I see; it is said "The Chief District of police then decided the protection of the school from the revenge of the students". This is what option 4 says. Remember that the correct answer is the one that does not contain information stated in the text. So I eliminate option 4. [Moves on to option 5] Ok; I remember. The police committed many abuses when they clashed with students. But I must read the text and see if this is true. [Skimming the text] Yes, I see; it is written here: "The so-called 'strong men' were accused for that offence. Phone cells, golden jewelry and money robbery was also observed. Some demonstrators were caught to be jailed". [Researcher asks a question: How do you know that the strong men refer to the police?] [Respondent replies] We know who the police are, what they do. We know that they consider themselves as strong because they have weapons and they use them on civilians. They are strong men. So I also eliminate option 5 . Let me see; oh I remain with option 2 only. I think it must be the answer. But I have to reread the text. [Rereads a portion of the text] Oh; you see? It says "driver was badly wounded" but option 2 says "the driver died as the lorry bumped a tree". This is not what the text says. Remember that I have to choose the option that contains information not stated in the text. So this is obviously the correct answer; no doubt.

4. Reads the text, but fails to understand the expectation of the question, and the meaning of (some) the options [item \#5]

The particularity of this test item that tests grammar knowledge in context is that the respondent, despite her reading of the part of the text referred to, is not capable to understand the expectation of the question, and the meaning of some options. Therefore, she proceeds to eliminate any options she fails to encode meaning. This extract is respondent's verbalization of her response decision process.

[Scans the part of the text referred to] I have read this part of the text. But I don't understand the meaning of 'hardly'. So, I can eliminate items that I don't understand. [Researcher asks: what does the question demand?] [Respondent replies] What 'hardly' means. So, I eliminate option 2, and option 4. [Then looks at option 1, thinking] Ah; I don't think happily can mean hardly; so I also eliminate it.

5. Reads the text, understands the expectations of the questions; but fails to understand the meaning and implication of (some) the options [item \#10, item \#12]

The striking feature of these test items is that they require inferencing skills as the information contained in the options should be related to the information that is implicitly stated in the text. Therefore, although they display a good understanding of the text and test question expectations, respondents eliminate all options where they fail to map information in the item into information in the text.

In answering item \#10, respondent \#4 eliminates the option that contains information implicitly stated in the indicated paragraph; although he is aware that this information is explicitly stated in another paragraph as main idea. This excerpt can act as evidence:

[Starts by reading the question; then, skims over the responses quickly and then goes back to the second paragraph]. Ah, I don't see a good answer. [Researcher asks: So what are you going to do?] [Respondent replies] Let me see if I can eliminate some options. [Rereads the second paragraph; and starts skimming options] Yes, I can eliminate option 3 because the information presented in this item is developed in paragraph 3; not paragraph 2. [Researcher asks: So, information in paragraph 2 does not relate to this option?] [Respondent replies] It does, but it is not clearly stated as in paragraph 3.

In answering item \#12, respondent \#4 reads the text, understands the question's expectations; but he fails to understand the meanings of options because he cannot make inferences in order to map information in the text to information in the options.

[Reads the question and the options; then goes back to the text and skims some parts; rereads the options]. I eliminate options 1, 2, 3 because this is not said in the text. [Looks at options 4 and 5, skims again the text, rereads the options]; 
this is not the way it said in the text; so I think these are wrong answers as well. [Researcher asks: So? No answer?] [Respondent replies] Let me first eliminate them also. [Researcher asks: So, no good answer?] [Respondent rereads the text and skims the five options] What the text says is not what is said here.

\section{Discussion}

The paper aimed to explore examinees' response decision processes they use when eliminating options in answering MC questions so as to evaluate whether the use of elimination of distractors strategy is construct-irrelevant as supported in the literature.

The results indicate five main patterns of response decision processes respondents used when eliminating distractors. However, of these five patterns, four patterns include response decision processes that can be qualified constructirrelevant to reading construct; and one pattern included response decision processes that appear to be construct-relevant. In reviewing the four patterns that included construct-irrelevant response decision processes, it was found that examinees selected their answers after eliminating some options without reading the text, and/or understanding the question's expectations and the meanings and implications of the (some) options. More specifically, the result indicate that examinees eliminated some options without a prior reading of the (portion of the) text when they could understand information contained in the options from simple logic or deductive reasoning; or when the question provided some clues to the answer. This finding appears to be consistent with a finding by Rupp, Ferne and Choi (2006) when they reported that for items with options that were close in meaning and plausibility, comprehension of the text content or general argument structure might have been subordinate to logical reasoning. Likewise, with some grammar-based items, examinees ignored reading the part of the text where the structure was located; preferring to eliminate options on the basis of their knowledge of the rule that governs the structure. Therefore, by answering an item without prior reading or recalling of the text information, any credit score provided after eliminating distractors brings irrelevant variance in the examinee actual test score. Furthermore, the results have indicated that examinees' tended to eliminate options when they could not understand the phrasing of the question, and this resulted in failing to relate information in the options to the information required in the question. Last but not least, it was found that when information necessary to falsify the five options was spread throughout the entire text, the examinee could read only some options and therefore eliminate other options out of a vague sense that they were incorrect; or they tended to eliminate options when text information was implicitly stated and failed to map it with information in the options. This finding is consistent with existing literature that suggests that when pieces of connected and relevant information necessary for answering a test item were not presented in close proximity, examinees could hardly make a mental representation of the text (Sheehan \& Ginther, 2001; Freedle \& Kostin, 1992); and that inference items, since they are perceived to be difficult, are more susceptible to the use of elimination of distractors strategy as they require examinees to engage with the whole text (Rupp, Ferne, \& Choi, 2006; Embretson \& Wetzel, 1987).

However, the one response decision processes pattern that appears to be construct-relevant included all the three criteria deemed necessary for validating the reading construct. The results have indicated that some respondents eliminated options after they had read and understood the text as well as the questions' expectations; and after they had evaluated the truth status of each option. More specifically, the results have suggested that with some items that required respondents to read information scattered in different parts of the text, the response decision process became more and more characterized by a continual back and forth between the options and relevant text sections in order to logically eliminate, that is, falsify potentially incorrect options. This process was continued until the potentially correct option could be confirmed. The use of this response decision processes reflects Embretson and Wetzel (1987)'s response decision processes as these respondents were able to connect different text propositions into a meaningful representation of the text; they could relate the information in the item question and options to the information in the text; and they could also falsify different options and confirm the answer option for accuracy (Embretson \& Wetzel, 1987). This finding, that validates the use of elimination of distractors strategy in answering MC reading items, is not consistent with existing literature that qualifies this strategy as simply construct-irrelevant (Sarnaci, 1979; Rupp, Ferne, $\&$ Choi, 2006) and associates it with general test-taking skills than with reading comprehension skills (Ozuru, et al., 2008).

\section{Conclusion}

The results of this study suggest that elimination of distractors strategy can be a construct-irrelevant strategy as well as a construct-relevant strategy. Therefore, this finding helps to interrogate studies that a priori consider elimination of distractors as a construct-irrelevant strategy without any prior investigation of the actual response processes examinees use when using this strategy.

This insight is significant in test wiseness research; especially research that aim to validate the reading construct from examinees' test taking strategies use perspective. By describing the actual response decision processes foreign language students use while eliminating distractors in a multiple-choice reading test, we can gain a better understanding of the relationship between the actual use of this strategy and the reading construct being measured. Such a relationship is important as it enables to take an informed conclusion on whether the elimination of distractors strategy is a constructrelevant or a construct-irrelevant strategy. Therefore, this insight is expected to augment our understanding of elimination of distractors as a test wiseness strategy that brings construct-irrelevant variance in test scores; and therefore affects test validity. This insight can inform psychometrically-driven studies that are grounded in the concept of partial 
knowledge by augmenting their understanding in their distinction between partial knowledge and absence of knowledge in answering MC items (Chang, Lin, \& Lin, 2007; Alexander, et al., 2001). Furthermore, these findings can inform assessment practices that support and use elimination testing to reconsider some of their assumptions on examinees' use of elimination of distractors strategy. Last, but not least, this research insight is meant to fill the gap on the abject paucity of studies relating to elimination of distractors strategy in MC reading tests in general (Stathopoulou, \& Nikaki, 2009) and the actual processes examinees engage when answering test items in particular.

The present paper has some limitations that are typical to the use of verbal reports (Cohen \& Upton, 2006). The fact that respondents were verbalizing their response decision processes as they worked through the items could have influenced their way of completing the task. Furthermore, since the completion of the test was not timed, and since their scores were of no consequence, it is also possible that respondents were making an effort to respond to each item more conscientiously than they would have responded under normal testing conditions. Last but not least, a distinction was not made between response decision processes that were used for test items that were answered correctly as opposed to those answered incorrectly; yet, such a distinction could have shed further insights into respondents' use of the different response decision processes. Nevertheless, the researcher feels that the data are indicative of the kinds of processes that respondents made in an effort to answer the ESE items.

\section{REFERENCES}

[1] Alderson, C.J. (2000). Assessing reading. Cambridge: Cambridge University Press.

[2] Alexander, M. W., Bartlett, J. E., Truell, A. D., \& Ouwenga, K. (2001). Testing in a computer technology course: An investigation of equivalency in performance between online and paper and pencil methods. Journal of Career and Technical Education, 18 (1), 69-80.

[3] Ascalon, M.E., Meyers, L.S., Davis, B.W., \& Smits, N. 2(007). Distractor similarity and item-stem structure: Effect on item difficulty. Applied Measurement in Education, 20(2), 153-170.

[4] Bajtelsmit, J. W. (1975). Development and validation of an adult measure of secondary cue-using strategies on objective examinations: The test of obscure knowledge. Paper presented at the annual meeting of the National Council on Measurement in Education, Washington.

[5] Bakker, M., Beijaard, D., Roelofs, E., Tigelaar, D., Sanders, P., \& Verloop, N. (2008). The impact of construct-irrelevant variance and construct under-representation in assessing teachers' coaching competence. In Bakker, M. Design and evaluation of video portfolios: Reliability, generalizability, and validity of an authentic performance assessment for teacher. Openaccess. leidnuiv.nl.

[6] Bradbard, D. A., Parker, D. F., \& Stone, G. L. (2004). An alternate multiple-choice scoring procedure in a macroeconomics course. Decision Sciences Journal of Innovative Education, 2 (1), 11-26.

[7] Cohen, A. \& Upton, T. (2006.). Strategies in responding to the new TOEFL reading tasks. Educational Testing Services, 666 Rosedale Rd Princeton, NJ 08540-2218.

[8] Chang, S.-H., Lin, P.-C., \& Lin, Z. C. (2007). Measures of Partial Knowledge and Unexpected Responses in Multiple-Choice Tests. Educational Technology \& Society, 10 (4), 95-109.

[9] Crehan, K. D., Koehler, R. A., \& Slakter, M. J. (1974). Longitudinal studies of test-wiseness. Journal of Educational Measurement, 11, 209-212.

[10] Diamond, J. J., \& Evans, W. J. (1972). An investigation of the cognitive correlates of test-wiseness. Journal of Educational Measurement, 9, 145-150.

[11] Embretson, S.E. \& Wetzel, D. (1987). Component latent trait models for paragraph comprehension tests. Applied Psychological Measurement 11, 175-93.

[12] Ericsson, K. A., \& Simon, H. A. (1993). Protocol analysis: Verbal reports as data. Cambridge, MA: MIT Press.

[13] Ford, V. A. (1973). Everything you wanted to know about test-wiseness. Princeton, New Jersey: Educational Testing Service, (ERIC Document Reproduction Service No. ED 093912).

[14] Gibb, G. B. (1964). Test wiseness as secondary cue response, (Doctoral dissertation, Stanford University), Ann Arbor, Michigan.

[15] Haladyna, T. M., Downing, S.M., \& Rodriguez, M. C. (2002). A Review of multiple-choice item-writing guidelines for classroom assessment. Applied Measurement in Education, 15(3), 309-334.

[16] Katalayi (2014). Fundamental validity issues of an English as a foreign language test: A process-oriented approach to examining the reading construct as measured by the DR Congo English state examination. Doctoral Dissertation, University of the Western Cape, South Africa.

[17] Lau, P. N., Lau, S. H., Hong, K. S., \& Usop, H. (2011). Guessing, Partial Knowledge, and Misconceptions in Multiple-Choice Tests. Educational Technology \& Society, 14 (4), 99-110

[18] Lee, J. (2011). Second language reading topic familiarity and test score: Test-taking strategies for multiple-choice comprehension questions. Doctoral thesis, The University of Iowa

[19] Messick, S. (1989). Validity. In R. L. Linn (Ed.). Educational measurement (3rd ed., pp 13-103). New York: American Council on Education? Macmillan.

[20] Millman, J. (1966). Test-wiseness in taking objective achievement and aptitude examinations. Final Report, College Entrance Examination Board.

[21] Nilsson, I., \& Wedman, I. (1974). On test-wiseness and some related constructs. Educational Reports, 7, 45-57.

[22] Oakland, T. (1972). The effects of test-wiseness materials on standardized test performance of preschool disadvantaged children. Journal of School Psychology, 10, 355-360.

[23] Oh, H. J. (2004). Reasoning test takers' guessing strategy and their understanding of formula scoring. Paper presented at annual meeting of the American Educational Research Association (AERA), San Diego, CA. 
[24] Rupp, A., Ferne, T., \& Choi, H. (2006). How assessing reading comprehension with multiple-choice questions shapes the construct: a cognitive processing perspective. Language Testing, 23(4), 441-474.

[25] Sarnacki, R. I. (1979). An Examination of Test-Wiseness In the Cognitive Test Domain. Review of Educational Research, 49(2) 252-279.

[26] Stathopoulou, M., \& Nikaki, D. (2009). Test-taking strategies in the KPG reading test: Instrument construction \& investigation results. JAL 25, 129-148.

Godefroid B. Katalayi holds a doctorate degree in language education from the University of the Western Cape, South Africa. He currently lectures English teaching methodology and language testing modules at the Department of English at Institut Supérieur Pédagogique de Kananga, DR Congo. He has also lectured Academic literacy and Method of English modules in the Faculty of Education, University of the Western Cape, South Africa. His research interest includes language assessment, the validity of reading tests, the assessment of narratives, and the teaching of grammar and reading to EFL learners. 